Int. J. Electrochem. Sci., 15 (2020) 7809 - 7820

\title{
Electrochemical fabrication of novel fluorescent Poly(pyrene-co- 3-methylthiophene) polymeric film
}

\author{
Wei Sun, Yeye Wang, Wenjun Ding ${ }^{*}$, Zuzhi Bai, Congcong Liu* \\ Jiangxi Key Laboratory of Organic Chemistry, Jiangxi Science and Technology Normal University, \\ Nanchang 330013, China \\ *E-mail: 1cc.0705@163.com and dingwenjun562@,163.com
}

doi: $10.20 .964 / 2020.08 .37$

Received: 5 April 2020 / Accepted: 29 May 2020 / Published: 10 July 2020

Poly(pyrene-co-3-methylthiophene), a new copolymer, was successfully synthesized by the direct electrochemical oxidation of a monomer mixture of pyrene and 3-methylthiophene in boron trifluoride diethyl etherate. The electrochemical performance of the copolymers was characterized by cyclic voltammetry. Ultraviolet visible (UV-vis) and Flourier transform infrared (FI-TR) were used to characterize the structure of the copolymers. In addition, the resulting copolymers were found to partially dissolve in some organic solvents (e.g., dimethyl sulfoxide). Fluorescence spectroscopy revealed that not only can the copolymers emit different photoluminescence under $365 \mathrm{~nm}$ UV light in the dimethyl sulfoxide solution, but also their emitting properties can be controlled by changing the monomer feed ratios.

Keywords: Electrochemical copolymerization, Conducting polymers, Poly(3-methylthiophene), Polypyrene.

\section{FULL TEXT}

(C) 2020 The Authors. Published by ESG (www.electrochemsci.org). This article is an open access article distributed under the terms and conditions of the Creative Commons Attribution license (http://creativecommons.org/licenses/by/4.0/). 